\title{
VARIABILIDADE INTERANUAL E MENSAL DO CLIMA EM PORTO ALEGRE/RS NOS PERÍODOS PROPÍCIOS A DOENÇAS VIRAIS TRANSMITIDAS PELO MOSQUITO AEDES AEGYPTI - 2014/2015 E 2015/2016
}

\author{
Bianca Marques Maio $^{(a)}$, Erika Collischonn ${ }^{(b)}$, Ricardo Brandolt ${ }^{(c)}$ \\ (a) Programa de Pós-graduação em Geografia, Universidade Federal de Pelotas, biankamaio@hotmail.com \\ (b) Departamento de Geografia /ICH, Universidade Federal de Pelotas, ecollischonn@ gmail.com

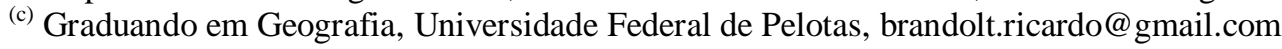

\section{Eixo: Climatologia em diferentes níveis escalares: mudanças e variabilidades}

\begin{abstract}
Resumo
O artigo trata da averiguação de variabilidade climática anual e mensal para o período do ano mais propício a proliferação de doenças virais transmitidas pelo mosquito Aedes aegypti, em Porto Alegre/RS, nos anos 2014/2015 e 2015/2016, bem como, do resultado da análise dos tipos de tempo que se sucederam nestes meses. Para os recortes temporais definidos, dados meteorológicos mensais foram comparados às normais climatológicas e relacionados às anomalias do El Niño-Oscilação Sul. Além disso, dados diários dos elementos climáticos, bem como de cartas sinóticas foram utilizados para definir a atuação dos sistemas atmosféricos e tipos de tempo. Como resultado, constatou-se diferenças claras entre o verão 2014/2015 e o verão 2015/2016 nas médias e totais mensais, nas anomalias globais e, ainda, na participação dos sistemas atmosféricos e tipos de tempo, o que pode ter corroborado para a diferencial ocorrência de dengue de um ano para o outro.
\end{abstract}

Palavras chave: variabilidade - massas de ar - tipos de tempo

\section{Introdução}

Estudos recentes têm apontado que o Aedes aegypti está se adaptando a condições climáticas adversas, por exemplo, de frio ou estiagem; porém, nas latitudes mais meridionais do Brasil, por enquanto, os casos de dengue autóctone têm um comportamento mais sazonal. Aumentam na condição de tempo mais favorável ao desenvolvimento do vetor (prevalência de temperatura mínima e máxima entre $22^{\circ} \mathrm{C}$ e $30^{\circ} \mathrm{C}$ com chuvas regulares, mas intermitentes), normalmente entre dezembro e abril, e diminuem quando fica mais frio e desfavorável. Além disso, os números totais variam muito de ano para ano e a frequência das ocorrências é variável, mesmo ao longo do período mais favorável. Esta variabilidade tem relação com a reintrodução do vírus ou de novos sorotipos do mesmo, com o grau de vigilância sanitária, tanto por parte do poder público, como da população. Supõe-se que também possa haver uma relação com a variabilidade climática anual e com a maior ou menor participação de um ou outro sistema atmosférico e com os tipos de tempo que deles resultam. 
Neste artigo apresenta-se um extrato de dissertação de mestrado desenvolvida no Programa de Pósgraduação em Geografia da UFPEL sobre a relação entre clima e dengue em Porto Alegre que, por sua vez, se integra ao projeto "CLIMA URBANO E DENGUE NAS CIDADES BRASILEIRAS: RISCOS E CENÁRIOS EM FACE DAS MUDANÇAS CLIMÁTICAS GLOBAIS (Processo CNPQ 404204/2013-9).

Assim, o artigo trata da averiguação de variabilidade climática anual e mensal e seus prováveis fatores, bem como, do resultado da análise dos tipos de tempo que se sucederam, em Porto Alegre/RS, nos meses mais propícios (de dezembro à abril) à proliferação de doenças virais transmitidas pelo mosquito Aedes aegypti nos anos 2014/2015 e 2015/2016.

Sartori (2016), em estudos realizados no Rio Grande do Sul, conseguiu identificar quinze tipos de tempo, reunidos em três grandes famílias, associadas aos dois grandes grupos de sistemas atmosféricos que influenciam a fachada atlântica da América do Sul. São eles: 1. Sistemas extratropicais, com seus mecanismos frontais, instabilizadores do tempo (FPA), e seus domínios anticiclonais polares de ações estabilizadoras (MPA); 2. Sistemas intertropicais, com seus domínios tropicais marítimos (MTA) estabilizadores do tempo e suas correntes tropicais continentais (MTC) com fluxos de oeste e noroeste, responsáveis por fortes aquecimentos pré-frontais instablizadores do tempo, antes de passagens frontais (Sartori, 2016, p.51).

Os tipos de tempo são respostas dadas pelos elementos meteorológicos, ao domínio ou avanço desses sistemas atmosféricos. Cada tipo de tempo tem uma característica que o define, própria da massa de ar ou sistema perturbado atuante. Por não existir uma terminologia climatológica consagrada nacionalmente, Sartori (2016, p. 52-70) definiu uma nomenclatura própria para cada tipo de tempo, segundo três grandes famílias:

1 Tempos anticiclonais polares: Tempo anticiclonal polar típico, Tempo anticiclônico polar marítimo, Tempo anticiclônico polar pós-frontal, tempo anticiclônico polar continental, tempo anticiclônico polar em tropicalização, tempo anticiclonal aquecido.

2. Tempos associados a sistemas intertropicais: anticiclônico tropical marítimo, anticiclônico tropical continentalizado, tempo depressionário continental.

3. Tempos associados a correntes perturbadas: Tempo frontal de sudoeste de ação moderada, tempo frontal de sudoeste de fraca atuação, Tempo frontal estacionário, Tempo frontal de nordeste, Tempo frontal ciclonal de ação direta, Tempo frontal ciclonal de ação indireta.

Sartori (2016) apresenta uma variedade de modalidades de atuação tanto da massa polar atlântica, quanto das massas tropical atlântica e tropical continental e, ainda, dos sistemas frontais. Neste trabalho, exceto a 
massa polar atlântica (MPA), todas as demais foram consideradas na sua tipologia mais genérica. A distinção da MPA em dois subtipos, ocorreu porque, no verão, a massa polar atlântica atua na região por apenas um ou dois dias e posteriormente começa a entrar rapidamente em processo de tropicalização, devido à maior insolação e à maior radiação solar absorvida pela superfície continental que caracterizam o verão. Por isso, neste trabalho foram utilizadas duas tipologias, massa polar atlântica e massa polar velha, assim denominada por Monteiro (1968). No período do ano escolhido, é mais frequente a segunda, que se caracteriza por registrar temperaturas máximas superiores à $25^{\circ} \mathrm{C}$ e mínimas superiores à $15^{\circ} \mathrm{C}$, podendo haver máximas absolutas superiores à $30^{\circ} \mathrm{C}$, com grande amplitude térmica diária, céu limpo e diminuição da umidade relativa especialmente à tarde (SARTORI, 2016).

\section{Metodologia}

Este trabalho se organizou em quatro etapas distintas. As primeiras duas referem-se ao trabalho com dados meteorológicos, das médias mensais aos dados diários e de sua distribuição nos recortes temporais propostos, de dezembro de 2014 a abril de 2015 e de dezembro de 2015 a abril de 2016. A terceira referese à organização dos dados da dengue por mês. Na última etapa, se analisa conjuntamente os dados no sentido de constatar possíveis relações.

Primeiramente, analisou-se os dados meteorológicos mensais para os recortes temporais em comparação às normais climatológicas e nas possíveis conexões com o El Niño-Oscilação Sul. Foram utilizados com referência de variabilidade dados do Niño 3.4 disponibilizados pelo NOAA, as normais climatológicas para Porto Alegre (1961-1990) e os dados mensais de temperatura (máxima, média e mínima) e de precipitação para a estação meteorológica convencional de Porto Alegre, disponível no banco de dados para apoiar as atividades de ensino e pesquisa e outras aplicações do INMET (Dados da Rede do INMET). Numa segunda fase do trabalho foi analisada, em mais detalhe, a sucessão de atuação das massas de ar ou sistemas perturbados nestes mesmos dois períodos, no intuito de caracterizar a participação dos sistemas atmosféricos e sua relação com os dados confirmados de dengue.

Para identificar estes sistemas atmosféricos atuantes diariamente foram utilizados como referência as cartas sinóticas das 12HMG obtidas no site da Marinha do Brasil (https://www.mar.mil.br). Complementarmente, foram utilizados os dados meteorológicos horários ou diários da estação automática do INMET da estação convencional de Porto Alegre. Assim, ainda que possam ter ocorrido dois tipos de tempo num dia, foi contabilizado o predominante no dia. Para facilitar a identificação, os dados foram organizados em gráficos próprios para a análise, que vinculam os elementos do tempo à dinâmica dos 
sistemas atmosféricos, os chamados gráficos de análise rítmica. Posteriormente, foi calculado o percentual de participação de cada tipo de massa de ar atuante por mês.

\section{Resultados}

3.1 O fenômeno El Niño-Oscilação Sul e a variabilidade climática no recorte temporal considerado

O El Niño e o La Niña são anomalias que representam uma alteração do sistema oceano-atmosfera (processos de troca de energia e umidade) no Oceano Pacífico tropical, e que tem consequências no tempo e no clima de diferentes partes do Planeta. O fenômeno El Niño-Oscilação Sul (ENOS) é caracterizado por anomalias, positivas (El Niño) ou negativas (La Niña), de temperatura da superfície do mar (TSM) no Pacífico equatorial, e sua caracterização é feita pela Administração Nacional Oceânica e Atmosférica (NOAA) através de índices, tais como o Índice de Oscilação Sul (IOS), calculado através da diferença de pressão entre o Taiti no Pacífico Central e Darwin na Austrália, bem como por outros índices nomeados Niño, complementado por um número (Niño 1+2, Niño 3, Niño 3.4 e Niño 4). Estes índices consideram as anomalias de temperatura da superfície do mar - diferença entre a temperatura observada real e um valor médio de referência, normalmente a média histórica de 30 anos - em diferentes regiões do Pacífico equatorial. O índice Niño 3.4 corresponde a anomalia entre os $5^{\circ} \mathrm{N}$ e $5^{\circ} \mathrm{S}$ e entre os $170^{\circ}$ e $120^{\circ} \mathrm{W}$.

A anomalia é positiva quando a temperatura real fica acima do valor médio. A anomalia é negativa quando a temperatura real fica abaixo da média. O El Niño é caracterizado por uma anomalia positiva de pelo menos $0,5^{\circ} \mathrm{C}$, por três trimestres consecutivos e ininterruptos. A La Niña é caracterizada por uma anomalia negativa de pelo menos $0,5^{\circ} \mathrm{C}$ no mesmo período.

O gráfico da figura 1 apresenta a variação destas anomalias entre os anos de 2014 e 2017.

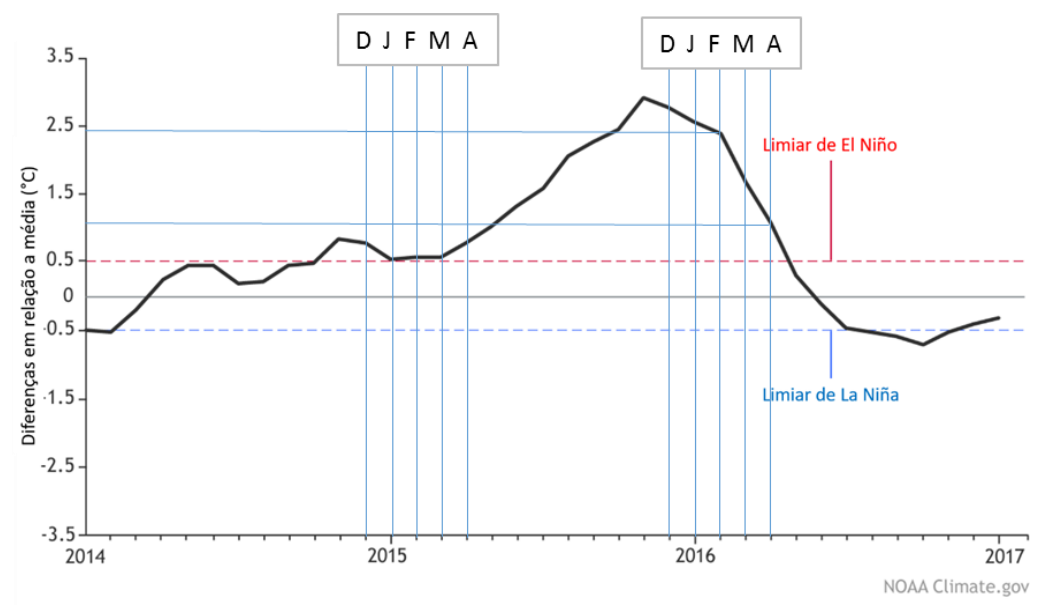




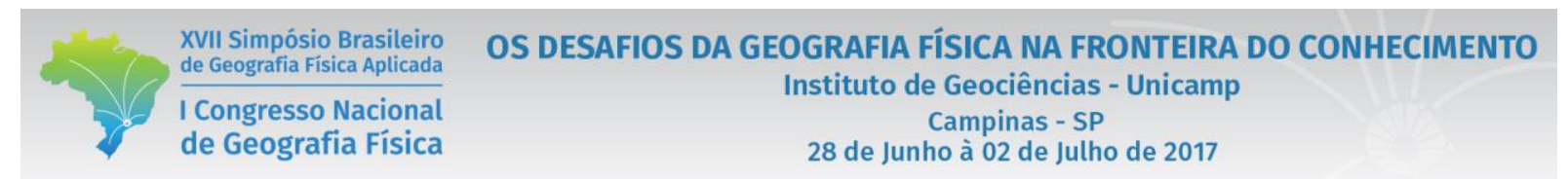

Figura 1 - Índice da anomalia da TSM na região Niño 3.4 de 2014 a 2017.

Fonte: NOAA Climate. National Centers for Environmental Information (modificado pelos autores).

Segundo os dados gráficos da figura e a maioria dos modelos do NOAA (National Oceanic \& Atmospheric Administration), a maior parte do ano de 2014 foi de ENSO neutro (índice Niño-3.4 entre $0,5^{\circ} \mathrm{C}$ e $0,5^{\circ} \mathrm{C}$ ). Nos meses finais de 2014 (outubro, novembro e dezembro), ocorreu um ensaio de El Niño, voltando ao valor de limiar nos primeiros meses de 2015. Os valores acima do limiar começaram a se registrar, efetivamente, em maio de 2015, e o El Niño 2015/2016 teve seu auge, no fim da primavera de 2015 e começo do verão 2016. A média da anomalia da temperatura da água do mar, na região Niño 3.4, no trimestre novembro/dezembro/janeiro chegou a $2,3^{\circ} \mathrm{C}$. Este valor foi igual ao máximo observado no evento El Niño 1997/1998. A partir de janeiro de 2016, ao longo do verão e do outono de 2016, as águas do Pacífico Equatorial foram ficando menos quentes e o El Niño 2015/2016 foi perdendo força. No mês de maio o desaquecimento das águas se acentuou e a anomalia da temperatura da água no mar no Pacífico Equatorial central começou a ficar negativa.

$3.2 \mathrm{O}$ período propício à doenças virais transmitidas pelo mosquito Aedes aegypti 2014/2015

O comportamento dos elementos climáticos em Porto Alegre no verão 2014/2015 apresentou, quanto às temperaturas, valores ligeiramente superiores ao da Normal Climatológica (1961-1990) nos meses de dezembro, janeiro, março e abril, enquanto o mês de fevereiro praticamente se igualou a normal. Já, quanto a precipitação, apresentou valores bem acima dos valores referência nos meses de dezembro e janeiro, enquanto fevereiro, março e abril registraram precipitação inferior às normais (Figura 2).

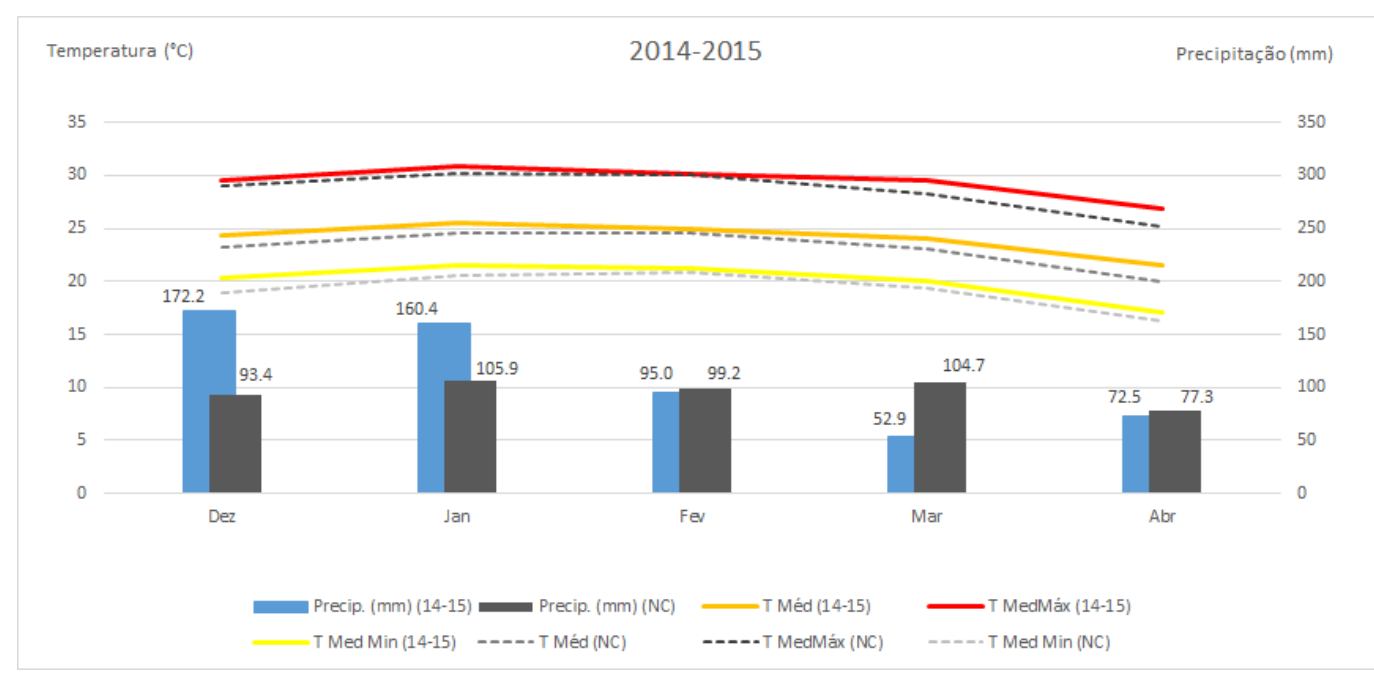

Figura 2 - Meses de dengue 2014/2015- Variação dos valores de temperaturas (máxima, média e mínima) e de precipitação mensal em relação às normais climatológicas (1961-1990). 
Estes dados parecem indicar uma relação com a TSM na região Niño 3.4 que, em novembro e dezembro de 2014, tinha apresentado valores acima do limiar dos $0,5^{\circ} \mathrm{C}$, em janeiro, porém, voltou a esse limiar, indicando um El Niño fraco. No mês de abril se intensifica a anomalia positiva da TSM (figura 1) que acarretará no El Niño de 2015.

A participação mensal das massas de ar no período mais propicio à dengue em Porto Alegre 2014/2015, resultante do método de identificação diário descrito, está apresentado na figura 3. Com resultado desta distribuição de massas de ar e baseado na classificação de Sartori (2016) foi possível fazer uma descrição dos tipos de tempos que se sucederam para esse mesmo recorte temporal.

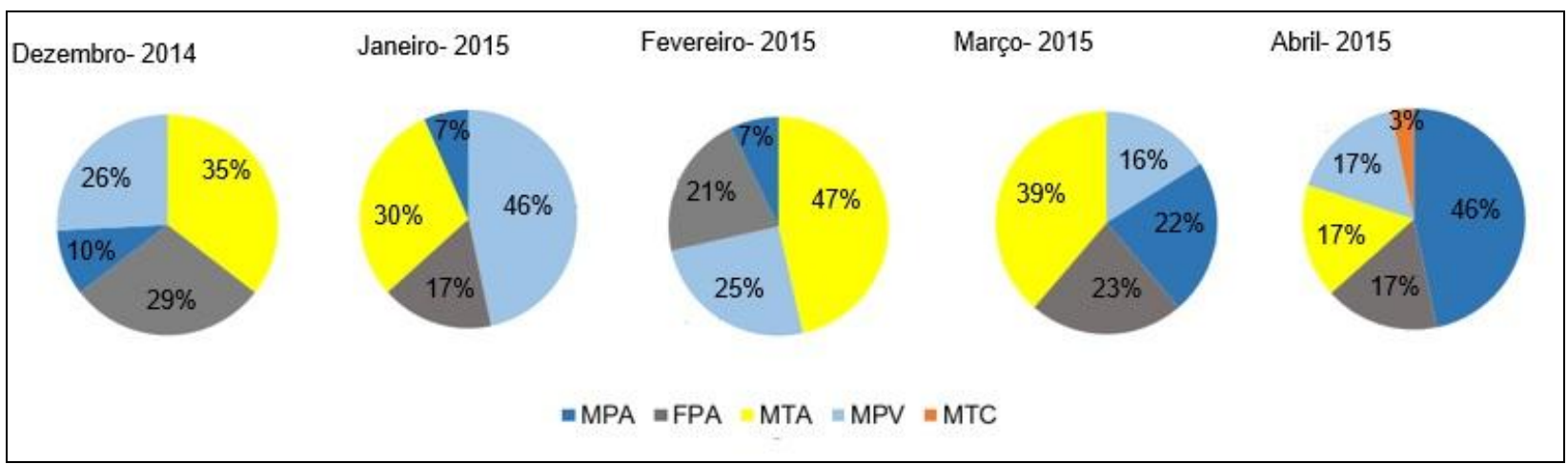

Figura 3 - Distribuição das massas de ar no período de dezembro de 2014 a abril de 2015 e Porto Alegre/RS

Dezembro é de maneira geral, fortemente marcado pela transição da primavera para o verão na porção meridional do território brasileiro, que fica cada vez mais aquecido. Assim, a massa polar atlântica, que dominava nos meses anteriores, chega ao território já perdendo rapidamente suas características de origem e, consequentemente, diminui sua frequência. Como resultado se tem o ar atmosférico cada vez mais topicalizado, a chamada "massa polar velha" que começa a dividir a atuação com a massa polar atlântica até sobrepujá-la.

Assim, para o mês de dezembro de 2014, pela identificação realizada, os sistemas extratropicais apresentaram a seguinte participação: $26 \%$ de atuação da massa polar velha (com dois dias de tempo ciclonal aquecido e seis dias de tempo anticiclônico polar em tropicalização), 10\% de 
atuação da massa polar atlântica (tempo anticiclonal polar típico 3 dias de atuação) e $29 \%$ de atuação de sistemas frontais (foram representados pelas frentes polares, quando convergiram em relação as características diferentes das massas de ar, uma de menor temperatura, vinculada ao avanço da massa polar atlântica, e outra de maior temperatura vinculadas a massa polar velha e a massa tropical atlântica, apenas em um episódio de atuação o sistema frontal ficou estacionário com duração de 3 dias consecutivos, no qual se observou um declínio significativo das temperaturas máximas e mínimas).

Neste mesmo mês, os sistemas extratropicais apresentaram 35\% de atuação com a presença da massa tropical atlântica, que liderou sua participação no mês marcada por permanência de atuação durante três ou mais dias consecutivos, principalmente na segunda e última semana do mês. O tipo de tempo decorrente dessa condição de continuidade da massa tropical atlântica foi o tempo anticiclônico tropical continentalizado; o outro tipo de tempo encontrado foi o tempo anticiclônico tropical marítimo, com sete dias de atuação e cujas características corresponderam a temperaturas elevadas (entre $19^{\circ} \mathrm{C}$ e $35^{\circ} \mathrm{C}$ ), com duração de no máximo dois dias consecutivos, em virtude de anteceder a chegada do sistema frontal (na maioria das vezes). Não foi identificado a atuação da massa tropical continental.

Em Janeiro de 2015, devido à diminuição ainda maior de atuação da massa polar atlântica (6\%), o sistema extratropical que mais atuou foi a massa polar velha, que liderou o mês com o valor correspondente a $52 \%$ de atuação. O tipo de tempo dela resultante foi o tempo anticiclônico polar em tropicalização (em 14 dias), devido a chegada frequente de anticlones de origem polar, porém com enfraquecimento muito rápido do ar polar sobre o continente chegando à Porto Alegre já totalmente tropicalizado e com aumento significativo das temperaturas máximas e mínimas. Nesse tipo de tempo também ocorreram algumas instabilidades atmosféricas pré frontais. Os sistemas frontais totalizaram sua participação em $16 \%$, a atuação do sistema frontal foi caracterizada pela diminuição da sua permanência que correspondeu no máximo dois dias de duração consecutivas. Os sistemas intertropicais se relacionaram a atuação da massa tropical atlântica, correspondente a atuação em $26 \%$ dos dias no mês que correspondeu a seis dias de 
tempo anticiclônico tropical marítimo e dois dias de atuação e o tempo anticiclônico tropical continentalizado.

No mes de Fevereiro de 2015 os sistemas extratropicais perderam forças resultando na participação de: massa polar velha (25\%), sob atuação da qual se identificou o tempo anticiclônico polar em tropicalização atuando por cinco dias consecutivos; massa polar atlântica (7\%) que atuou apenas em dois dias consecutivos (tempo anticlônico polar marítimo); e os sistemas frontais, que corresponderam a $21 \%$ de participação, cujo máximo de permanência foram dois dias consecutivos. O sistema intertropical com o domínio da massa tropical atlântica liderou na atuação do mês (47\%). O tipo de tempo resultante foi o anticiclônico tropical marítimo que, diferentemente dos outros meses, dobrou seu período de atuação, deixando a maioria dos dias com predominância de céu limpo e temperaturas entre $19^{\circ} \mathrm{C}$ e $35^{\circ} \mathrm{C}$.

Em Março de 2015, o começo do mês começou bem quente e registrando suas maiores temperaturas com a presença do tempo anticiclônico tropical continentalizado sob atuação da massa tropical atlântica (39\%), porém, mesmo com o predomínio dessa massa de ar no mês, os sistemas intertropicais começam a ganhar força novamente e principalmente a massa polar atlântica (22\%) volta a atuar aumentando a permanência de suas características e diminuindo a participação da massa polar velha (16\%) e os sistemas frontais totalizaram suas participações com 23\%, já na última semana do mês começaram os registros das menores temperaturas e o fim do período mais quente da região.

No último mês da análise para o ano 2015, abril, os sistemas extratropicais lideraram a atuação com as massas: polar (46\%), polar velha (17\%) e os sistemas frontais (17\%), isso significa um resfriamento. Os sistemas intertropicais participaram com a massa tropical atlântica (17\%) e a massa tropical continental (3\%), cuja atuação foi registrada em apenas um dia. Os tipos de tempo que se sucederam relacionados aos sistemas intertropicais foram, respectivamente, anticlônico tropical marítmo, que partir do meio do mês ela não atuou mais, e anticiclonal aquecido.

$3.2 \mathrm{O}$ período propício à doenças virais transmitidas pelo mosquito Aedes aegypti 2015/2016 


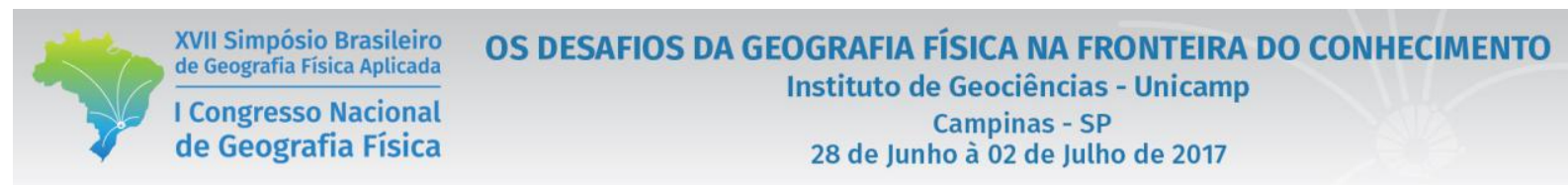

No período que corresponde ao verão de 2015/2016, evidencia-se para Porto Alegre, inicialmente, semelhança às médias históricas, porém a partir da metade do período analisado ocorrem bruscas variações termo-pluviométricas (Figura 4). Quanto a temperatura, observa-se que nos meses de janeiro e fevereiro a temperatura foi superior à normal climatológica, mas o que se destaca no gráfico é a chuva bem acima da média nos meses de março e abril e a permanência de temperaturas mais altas no mês de abril O cenário térmico das águas superficiais do Pacífico (Niño 3.4) indicou, a partir de janeiro, uma diminuição da temperatura, saindo dos elevados $3,4^{\circ} \mathrm{C}$ de TSM registrados em novembro de 2015 , passando por aproximadamente $2,4^{\circ} \mathrm{C}$ em fevereiro, até chegar por volta de $1{ }^{\circ} \mathrm{C}$ mais aquecido em abril de 2016.

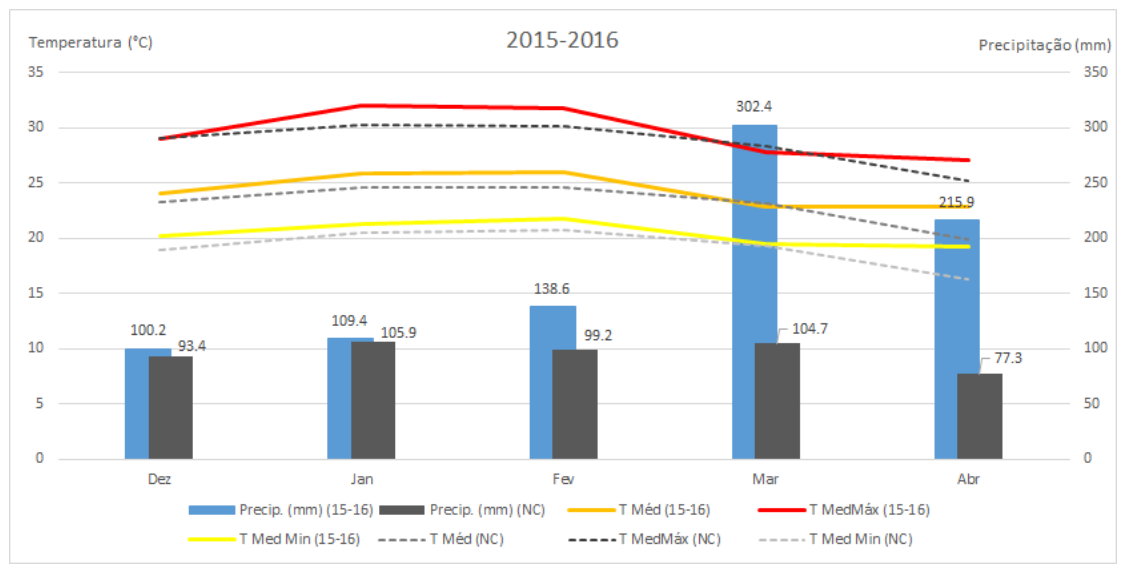

Figura 3 - Meses de dengue 2015/2016- Variação dos valores de temperaturas (máxima, média e mínima) e de precipitação mensal em relação às normais climatológicas (1961-1990).

A figura 4 apresenta a distribuição das massas de ar e sistemas perturbados para estes mesmos meses.

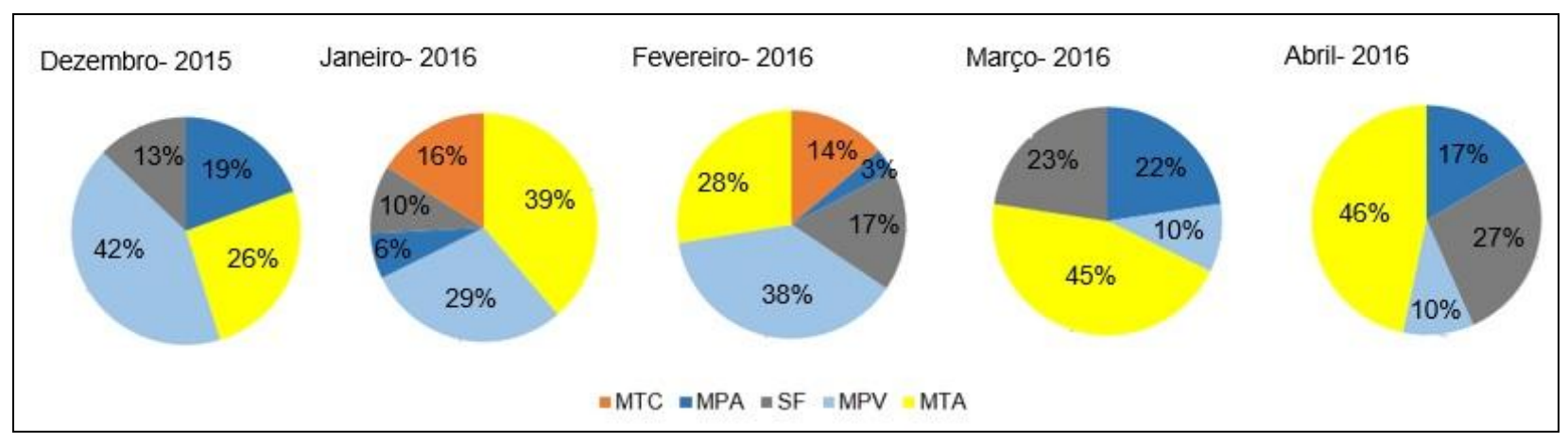

Figura 5 - Distribuição das massas de ar no período de dezembro de 2015 a abril de 2016 e Porto Alegre/RS 
Em relação a distribuição das massas de ar, dezembro de 2015 o mes começou frio e com a atuação dos sistemas extratropicais: massa polar atlântica (19\%), tempo anticlônico polar marítimo atuou em 6 dias, massa polar velha (42\%) tempo anticlonal aquecido atuou em 13 dias e até 6 dias consecutivos e os sistemas frontais (13\%) 4 dias com duração de apenas um dia. Os sistema intetropical foi a massa tropical atlântica, que atuou 8 dias (26\%) e os tempos foram; anticiclônico tropical continentalizado e anticiclônico tropical marítimo.

Janeiro de 2016 foi um mês quente com registro de temperatura máxima de $39^{\circ} \mathrm{C}$ e os resultados das distribuições das massas de ar foram: massa tropical atlâtica (39\%), 12 dias de atuação com máximo de cinco dias de atuação em sequencia os tipos de tempos que ocorreram foram; tempo anticlônico tropical continentalizado 4 dias e anticiclônico tropical marítimo 8 dias de atuação, massa tropical continental, em que se registraram as maiores temperaturas máximas com o tempo depressionário continental 5 dias de atuação sendo 2 dias consecutivos, os sistemas frontais totalizaram 10\% em 3 dias não consecutivos de atuação, massa polar velha (29\%) 9 dias de atuação e se dividiu em tempo anticiclônico polar em tropicalização 5 dias, 4 consecutivos e o tempo anticiclonal aquecido 4 dias no máximo 2 dias consecutivos e por último a massa polar atlântica (6\%) com dois de atuação atuando após a passagem do sistema frontal.

Em fevereiro de 2016 também foram registradas temperaturas altas, principalmente com a atuação da massa tropical continetal que teve um total de $14 \%$ de atuação em 4 dias sendo dois consecutivos outro sistema intertropical que deixou o ar atmosférico aquecido foi a massa tropical atlântica (28\%), num total de 8 dias com no máximo 4 dias consecutivos e os tempos anticiclônico tropical marítimo e tempo anticlônico tropical continentalizado, o sistemas frontais (17\%) não derrubaram as temperaturas altas e tiveram fraca intensidade, a massa polar velha teve a maior atuação no mês com $38 \%$, ela estava bem aquecida e o tempo que sucedeu foi o anticiclônico polar em tropicalização 11 dias sendo 4 dias consecutivos.

No mês de março de 2016 os sistemas extratropicais voltaram a atuar com mais força, massa polar atlântica (22\%) atuou em 7 dias nas passagens dos sistemas frontais diminuindo as temperaturas máximas e minímas, massa polar velha (10\%) atuou em apenas três dias aquecendo as caracteristicas da massa polar atlântica, sistemas frontais (23\%) nesse mes a passagem das frentes diminuiram significativamente as 
temperaturas mínimas e máximas e teve atuação em 3 dias consecutivos. Os sistemas intertropicais teve a atuação massa tropical atlântica (45\%) com o total de 14 dias de atuação, tempo anticiclônico marítimo.

Por último, em abril de 2016 a atuação da massa tropical atlântica foi de $46 \%$ atuando em 14 dias e em 7 dias consecutivos. A massa polar passou a atuar a partir dia 25/04/2016 diminuindo significativamente as temperaturas máximas e mínimas, deixando o RS com características de inverno mesmo estando no outono, o tempo que sucedeu foi o tempo anticiclônico polar coninental que durou 4 dias consecutivos e afastou o calor da região, a massa polar velha restringiu sua participação a $10 \%$, equivalente a 3 dias de atuação e os sistemas frontais totalizaram em 8 dias (27\%), com no máximo 2 dias consecutivos.

\section{Conclusões e considerações}

A análise mensal dos dados meteorológicos demonstrou que os anos de 2014/2015 e 2015/2016 foram significativamente distintos, primeiramente porque o período quente de 2015/2016 foi bem mais quente e chuvoso que o do ano anterior. Ha também um indicio de que o comportamento destes dados tenha relação com o El Niño - Oscilação Sul, pelo menos com o Niño 3.4 aqui considerado. O El Niño 2015/2016 teve seu auge, no fim da primavera de 2015 e começo do verão 2016. A média da anomalia da temperatura da água do mar, na região Niño 3.4, no trimestre novembro/dezembro/janeiro chegou a $2,3^{\circ} \mathrm{C}$. Este valor foi igual ao máximo observado no evento El Niño 1997/1998.

Da mesma forma a participação das massas de ar e sistemas perturbardos foi muito distinta de um ano para outro, principalmente em relação aos sistemas intertropicais, registra-se a atuação por mais tempo da massa tropical continental por mais tempo nos meses de janeiro/2016 e fevereiro/2016, elevando as temperaturas minimas e máximas consideravelmente. O último mês de análise, abril/2016, também mostrou um contraponto na distribuição das massas de ar em relação a massa tropical atlântica que atuou por mais tempo, deixando o ambiente com caracteristicas ambientais favoráveis a proliferação da dengue, já na última semana do mês, a atuação da massa polar atlântica mudou as características atmosféricas e, consequentemente as condições ambientais ideais para o desenvolvimento do mosquito da dengue com a formação do tempo anticiclônico polar continental.

Em relação aos dados de dengue para os períodos 2014/2015 e 2015/2016 (Figura 6), estes mostram uma diferença considerável de um período para o outro, tanto os casos importados como os casos autóctones. 
Nota-se que os casos autóctones, ou seja, resultantes de vetores que se criaram na cidade, são consideravelmente maiores no período 2015/2016 (294 casos) do que no anterior (12casos), porém também no período 2015/2016 muito mais gente trouxe o vírus de outras localidades, visto que foram 32 casos importados, no período de 2014/2015, e 97 casos, no período de em 2015/2016.

\begin{tabular}{cccccccc}
\hline & & Dezembro & Janeiro & Fevereiro & Março & Abril \\
\hline \multirow{2}{*}{$2014 / 2015$} & Casos importados & 0 & 3 & 3 & 7 & 19 \\
& Casos autóctones & 0 & 0 & 1 & 4 & 7 \\
\hline & & Dezembro & Janeiro & Fevereiro & Março & Abril \\
\hline \multirow{2}{*}{$2015 / 2016$} & Casos importados & 4 & 20 & 21 & 33 & 19 \\
& Casos autóctones & 0 & 5 & 63 & 114 & 112 \\
\hline
\end{tabular}

Figura 6 - Casos de dengue mensal no período 2014/2015 e 2015/2016 em Porto Alegre/RS. Fonte: PMPA/SMS/Vigilância Sanitária de Porto Alegre 2016.

A análise demonstrou que, no recorte temporal escolhido neste trabalho, há uma relação do número de casos de dengue com a variabilidade climática anual, bem como, com a maior ou menor participação de um ou outro sistema atmosférico e tipos de tempo resultantes.

\section{Bibliografia}

DHN - CENTRO DE HIDROGRAFIA DA MARINHA - SERVIÇO METEOROLÓGICO DA MARINHA. Cartas sinóticas. Disponível em: 〈https://www.mar.mil.br/dhn/chm/meteo/prev/cartas/cartas.htm>. Acesso em: 01 mar. 2017.

INMET- INSTITUTO NACIONAL DE METEOROLOGIA. Bdmet- dados históricos. Disponível em: <http://www.inmet.gov.br/portal/>. Acesso em: 01 mar. 2017.

INMET- INSTITUTO NACIONAL DE METEOROLOGIA. Normais Climatológicas do Brasil 1961-1990. Disponível em: < http://www.inmet.gov.br/portal/index.php?r=clima/normaisclimatologicas/>. Acesso em: 01 mar. 2017.

MENDONÇA, Francisco A.; Souza, Adilson V.; DUTRA, Denecir A. Saúde pública, urbanização e dengue no Brasil. In: Sociedade e Natureza (Online) vol.21 no.3 Uberlândia, Dec. 2009. Diponível em < http://www.scielo.br/scielo.php?script=sci_arttext\&pid=S1982-45132009000300003> Acesso em 20 Mar 2017.

MONTEIRO, C.A. de F. Clima. In Geografia do Brasil: Grande Região Sul. Rio de Janeiro: IBGE. V.4, TOMO 1, p-114-166. 1968.

PMPA/SMS/ BOLETIIM SEMANAL CGVS. Dados dengue, zika, chikungunya 2016 - se 01 a se 52. Disponível em: <http://www.ondeestaoaedes.com.br/default.php?reg=23\&p_secao=41>. Acesso em: 05 mar. 2017.

SARTORI, M. G. B. O vento Norte. Santa Maria: s.n., 2016. 256 p.

NOAA/ National Centers for Environmental Information. Equatorial Pacific Sea Surface Temperatures, 2017. Disponível em<https://www.ncdc.noaa.gov/teleconnections/enso/indicators/sst.php> 